\title{
Key Issues and Challenges in Developing Integrated Road Networks Infrastructure With Regional Connectivity: A Study Case of Porto-novo in the Republic of Benin
}

\author{
Dossa Didier Boko-haya ${ }^{1,2}$, Yadong $\mathrm{Li}^{1}$, Xiaoxian Liao ${ }^{1}$, Changrong Yao ${ }^{1}$, Chongjiao Wang ${ }^{1}$, and Qiqi Xiang ${ }^{1}$ \\ ${ }^{1}$ School of Civil Engineering, Southwest Jiaotong University, Chengdu 610031, China \\ ${ }^{2}$ Polytechnic School of Abomey-Calavi (EPAC), University of Abomey-Calavi (UAC), 01 POB: 526 Cotonou, Republic of Benin
}

\begin{abstract}
In recent years, with the rapid and continuous increase in traffic demand, a new upsurge in the construction of transport system is being made in Porto-novo. Thus, the problem of how to make modal transport system in this area play its full role and make its helpful to the development of integrated multimodal transportation networks needs to be urgently put forward. Recognizing these needs, this paper systematically addresses key issues and challenges toward developing integrated multimodal national transportation networks in the banded development axis of Abomey-Calavi-Pkota, Cotonou and Porto-novo with an emphasis to regional connectivity. Particularly, the paper addresses issues with the planning process, institutions, governance, strengths and weaknesses, funding and integrated multimodal development.
\end{abstract}

\section{Introduction}

In nowadays globalized and interdependent world, the development of integrated multimodal transportation systems and networks with regional connectivity is extremely vital for the socio-economic developments of any country. Located in the east part of Benin Republic and also situated at the east of Cotonou, Porto-novo is known as "the Political Capital of Benin" and is the traffic hub and material distribution center of road transport system in southeastern of Benin Republic and Federal Republic of Nigeria. As depicted in Figure 1, Porto-novo is surrounded by Abomey-Calavi and Cotonou and by Nigeria Republic from three sides (e.g., west, south and east) with a long boarder of hundreds of kilometers. As such, Porto-novo needs to develop well balanced integrated multimodal transit systems, road networks, bridges, rail, maritime and fluvial transport, by best using the natural strength of each individual mode for the efficient movement of passengers and goods as well as integrate itself with the local, national and regional countries particularly with Nigeria to expand international trades through transportation networks [1].

Mobility is the engine of economies and is extremely vital for the communication functioning of society. In this sense, being a signatory of West-African highway and Trans-Benin-Niger railway networks, Benin through Porto-novo has the obligation to develop its share of road and rail networks for seamless connection with the region and beyond. The country shares the vision and the strategic goals embraced by ECOWAS, NEPAD, African Union, and WAEMU, as well as the governance principles adopted at sub-regional and regional levels [2]. As a member country of West-African Association for Regional Cooperation (WAARC), African Union (AU), and other Regional Forums (RF), the banded development axis of Abomey-Calavi-Kpota, Cotonou and Porto-novo and other regional countries (Nigeria and Togo) cities have shown significant interest to improve transport connectivity among the regional countries for trade, tourism and commerce development purpose (Boko-haya, 2016, 2017). Specifically, Togo, Benin and Nigeria have expressed interest to utilize transport infrastructures (e.g., road, rail and ports) of Benin for bilateral trade as well as for transshipment and transit purpose. Besides, the Federal Republic of Nigeria has expressed interest to connect some cities with Benin through Porto-novo by roads and water ways.

Recognizing that Porto-novo becoming increasingly established as Benin's political capital, large steps are being conducted to alleviate these pressures through a range of improvement of infrastructure projects within the city and its surrounds area. For this purpose, the development of transportation in Porto-novo has been heavily biased towards road and with hundred kilometers of highways such as national, regional and district roads and bridges, road network becomes the dominant mode of transport with a modal share of over $93 \%$, while the investment level in railway and inland waterway sectors are very minimal [3-4]. Being a riverine city with many rivers, the waterways could have also been developed well in this area. Nonetheless, despite a large share of investment, Porto-novo road network system capacity is considerably inadequate. 
As a means of achieving sustainable and cost effective integrated multimodal transportation systems at the banded development axis of Abomey-Calavi-Kpota, Cotonou and Porto-novo and other regional countries (Nigeria and Togo) cities level for the efficient movement of people and goods as well as to serve as a regional transportation hub, Benin through Porto-novo needs to exercise a sound multimodal transportation planning process for the identification, prioritization and selection of implementable transportation infrastructure projects under its own budget constraints. The focus of the presented planning process would be to support by the NGB policies and priorities in this the area of Porto-novo. In addition, it requires strengthening institutional capacities and overcoming institutional barriers for the unbiased modal developments.

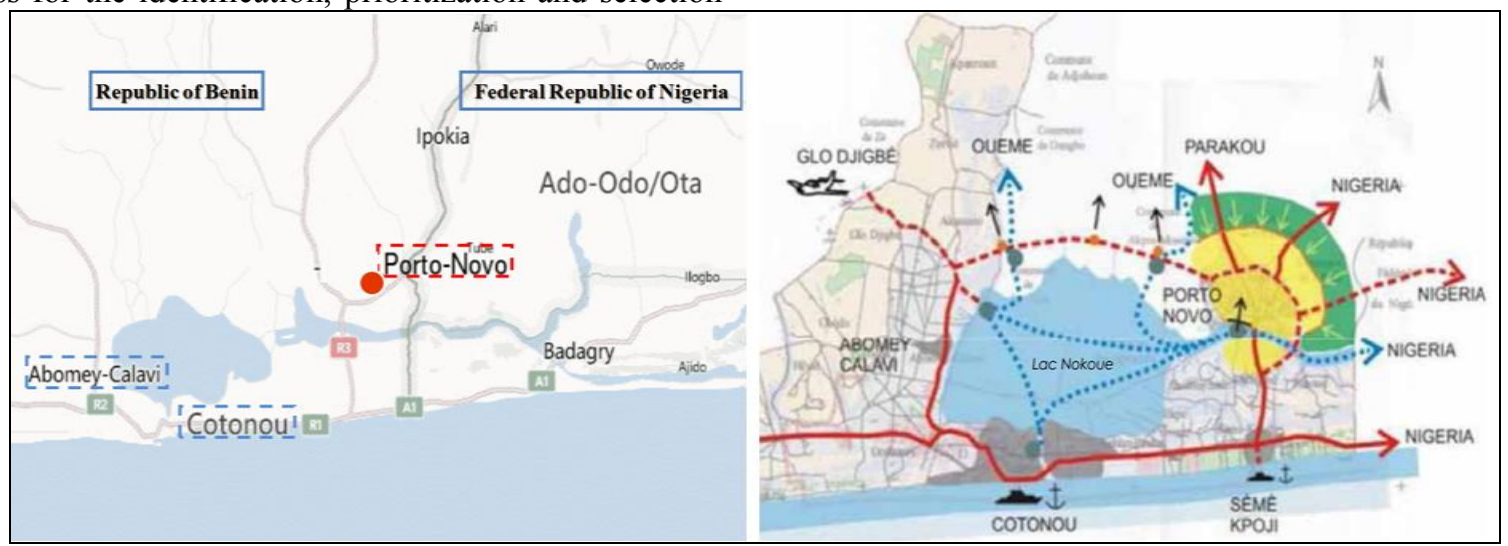

Figure 1. Geographical location of Porto-novo, Republic of Benin

\section{Overview of the study area}

\subsection{Transport policies and plans in Porto-novo}

As part of the Millennium Development Goals (MDGs), women equity, gender equity and poverty alleviation are some of the major goals of the authorities of this city where policies and programs are also formulated to achieve such goals. In this regard, the National Development and Reform Committee (NDRC), Planning Commission (PC), West African Urban Planning and Design (WAUPD) of Benin formulate long term prospective plans and short term five years plans on a rolling basis for all sectors including transportation sector [5-8]. Presently, Porto-novo has been formulating its five years plan (2016-2020). This five year plan includes the wish list of development programs and projects encompassing all sectors. However, these plans are developed without any commitments of funds for the implementation purpose. As such, many programs and projects are not implemented in a timely manner or even within the planning time frame (World Bank, 2013).

Porto-novo was stripped of its attributes of capital in the $60 \mathrm{~s}$ and $70 \mathrm{~s}$ with the transfer of the Presidency and the Ministries to Cotonou. With the advent of democratic renewal in 1990, the status of capital of Benin was reconfirmed and Porto-novo resurgence was emphasized with the implementation of a Special Rehabilitation Program (SRP) with the main goal to restore attributes to the city as Benin Republic capital. As part of the reform of territorial administration and decentralization [9-10], Law No. 98-005 of 15 January 1999, gives Porto-novo, as the capital, a common character with special status, 5 quarters and 86 districts. Table: 1 listed the identified weaknesses and strengths of Porto-novo city.

Table: 1 Identified weaknesses and strengths of Porto-novo city

\begin{tabular}{ll}
\hline \multicolumn{1}{c}{ Weaknesses } & \multicolumn{1}{c}{ Strengths } \\
\hline - Difficulties in establishing itself as Benin capital near the economic capital & $\bullet$ Capital of Benin Republic \\
- Road Network, bridges and infrastructure far below the needs of the population & $\bullet$ Economic benefits from trade with Nigeria \\
- Inadequate urban services & $\bullet$ Environment quality, unpolluted, along the lagoon \\
- Weak mobilization of financial resources & $\bullet$ Very largely composed of Green Spaces \\
- Development anarchic areas not surveyed and unrenovated & $\bullet$ Built Heritage (African, Afro-Brazilian colonial) \\
- Instabilities of resources from the informal trade & $\bullet$ Knowledge of quality craftsmanship \\
- Structure of tourist reception inappropriate & $\bullet$ A growing structure industry \\
- Difficulties in collecting taxes and tax & \\
- Low effective project management system & \\
- Governance decision fail to strike a balance between long term development & \\
\hline
\end{tabular}

The city of Porto-novo is likely the valuable and most different heritage of any city in Benin economic foundation is weak, despite its superior geographical location advantage. Adjustment is the critical deficiency 
in modern farming structure, the secondary industry development is restricted and the tertiary industry just starts. All these impedes Benin economic development [11-12].

\subsection{Regional connectivity: convenient and practical consideration of notable infrastructure development for Porto-novo City}

Communities with suitable public transit systems are economically booming communities and offer location advantages to businesses and individuals choosing to live or work in them. Thus, in recent years, Porto-novo (Benin) and Nigeria have made some good progress in the improvement of transportation connectivity between these two neighboring countries. Porto-novo authorities, through its latest Municipality Integrated Multimodal Transport Policy (MIMTP) 2016, has expressed the need of developing integrated multimodal sustainable transportation systems by efficiently inter-connecting road networks, bridges, rail, (e.g., sea ports and land) waterway transport (Boko-haya et al., 2016). As stated in the prospective plan 2015-2050, "the main objective of the perspective plan with respect to transportation is to develop an efficient, safe, sustainable and regionally balanced transportation system in which various modes complement each other, interface properly and, where possible, provide healthy competition to each other $[6,8] . "$

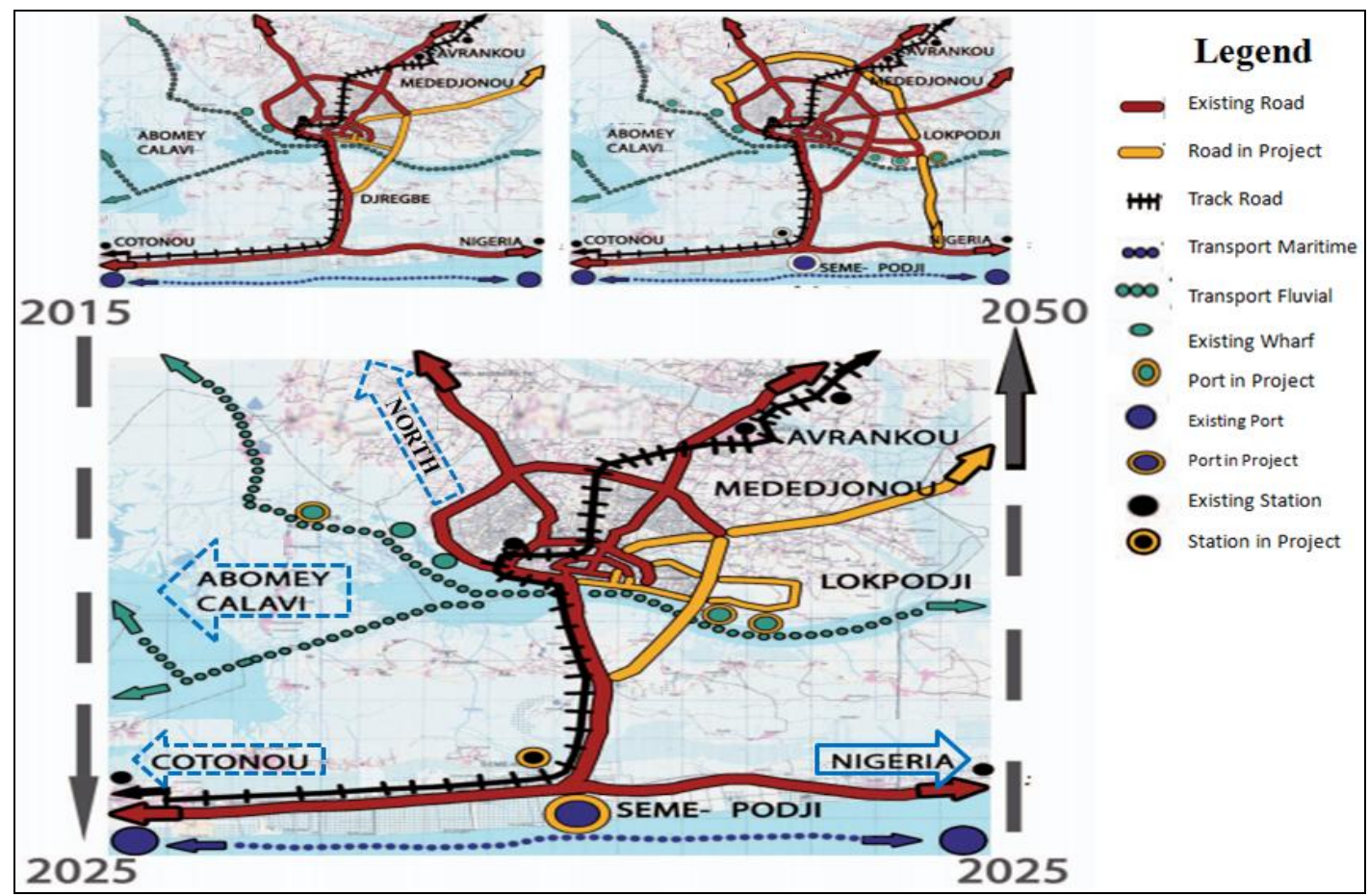

Figure 2. Evolution of the transport's map from the area of Porto- novo, Benin between 2015-2050.

-City of Abomey-Calavi Municipality (Glo-Djigbe Airport, and new bridge \& road networks to be built over Nokoue lake) - City of Cotonou (Economic Capital) Metropolitan Municipality (Airport, Sea port and Nokou lake road network to be built) - City of Porto-novo (Political Capital) Metropolitan Municipality (Waterways, new bridge and road networks to be built)

The prospective plan further gives importance to redevelop three main cities (Porto-nono, Cotonou and Abomey-Calavi) and also two main sea-ports (e.g., SemePodji and Allada sea ports) and efficiently connect them with the national transportation networks for seamless movement of people and goods. Further, the plan focuses on improving rail connectivity between Cotonou and Porto-novo as well as improving roadway connectivity with the regional countries including Nigeria and Togo. It also gives importance to improve connectivity between rural roads, maritime and fluvial transport which where feasible in area of Abomey-Calavi-Kpota (crossing nokoue lake), Cotonou and Porto-novo. The construction of a road with a new bridge, transport of passengers and the construction of new debarkations as well as train (track road) rehabilitation and construction of freight's harbor in Sèmè Kpodji. Thus, freight could arrive by the harbor and then will go in all the area by the train. The Porto-novo modern road network city, helps traffic move around Cotonou, Nigeria and Abomey-Calavi more easily and is essential for Benin economic growth. Thus, Portonovo has convenient modal traffic, it roads cross the city center, which connects then Porto-novo with Cotonou, Abomey-Calavi-Kpota and Nigeria. The national highway RNI1, 2 and 3 [9], Cotonou-Porto-novo expressway and Cotonou-Porto-novo railroad cross the south-east part of Benin. Porto-novo has basically achieved the goal that linking each village with highways, port and sea port. It's well developed in the east and has formed network-based highway pattern as shown in Figure. 2. 


\section{Analysis of transport's map evolution}

Through the analysis of Porto-novo's environment resources, socio-economic conditions, and super ordinate planning, the city positions itself as a living area for Benin county's development, inter-connecting road networks, bridges, rail, (e.g., sea ports, and land) maritime and fluvial transport. However, the study found that there are weaknesses in the planning process and prioritization of infrastructure projects that have prevented to achieve the intended benefits from the investments. Actually, there is no comprehensive coordinated, and continuous multimodal transportation planning process in the identification, prioritization and selection of transportation infrastructure projects (e.g., rail, road and inland water) that would measure the achievements of policy goals and objectives.

Several other ministries have the responsibilities on the surface transportation development activities. For instance, Ministry of Planning, Economic Restructuring and Employment (MPREPE), Ministry of Decentralization, Local Governance, Administration and Territorial Development (MDGLAAT) coordinates the activities of the territorial administration, regional and national roads, rails, bridges and rural roads, are under the jurisdiction of Ministry of Public Works, Transport and Urban Planning, Ministry of the Environment and Sustainable Development (MCVDD) and inland waterways and ports are under the Ministry of Maritime Economy and Shipping [2]. Mostly, projects are identified, prioritized and selected severally along modal lines by the respective modally segregated ministries or subordinates agencies in association with the Ministry of Planning. In Benin, such an approach often takes place under the influence of politics and without a comprehensive project evaluation. What is more, there is no formal public participation or involvement in the planning and infrastructure project development process.

Due to lack of funds or other reasons, unnecessary projects are frequently implemented and important projects infrastructure are postponed. Despite, NGB has given much attention to develop transport infrastructure projects through Public Private Partnership (PPP) agreements in the five year plan (2014-2018), however, the intended results has not been achieved during the planning period (Boko-haya et al., 2016, 2017). The NGB fiscal budget consists of two parts including development budgets or Annual Development Program (ADP) and non-development (revenue). The funds for the revenue budget come from NGB authorities' sources. However, as the NGB has very limited financial resources for the development budget, Benin relies on the international development partners (e.g., African Development Bank, World Bank, International Monitory Fund etc) to bridge the development budget gap while compromising NGB priorities and needs. The limited ADP funds are allocated to selected sectoral programs and projects and the implementation process of funded programs and projects infrastructure begins during the same fiscal year although some projects may last for multiple years. As a central planning authority, the PC in collaboration with the Ministry of Finance plays a key role in the preparation of programs and projects to be included in the ADP for funding during each fiscal year.

\section{Integrated transportation development needs}

Based on the diagnostic analysis, Porto-novo is still far away from developing modally balanced integrated multimodal transportation systems. Especially, Portonovo needs to invest heavily in the maritime, fluvial transport and rail sectors. Since Porto-novo, Cotonou and Nigeria share approximately 60 trans-boundary rivers, the collaboration of Porto-novo (Benin) and Nigeria in the joint development of waterways as well as costal shipping would be very beneficial for both the countries. Porto-novo and Abomey-Calavi-Kpota can conveniently be connected with many destinations.

With well developed and integrated multimodal transportation systems, Porto-novo can be able to use waterways for trade with Abomey-Calavi-Pkota and Nigeria and provided that the inland waterway ports are physically integrated with major roads, highways and rail transportation networks and hubs. For instance, Nokoue lake in Cotonou can be well connected with roads and even rails. Lokpodji can also be connected with AbomeyCalavi via waterways. In this view, significant investment will be needed in the development of inland waterway ports. Aids service would be needed to dredging work to maintain appropriate channel depths and night navigational. These activities will be carried/contracted out with the involvement of the private sectors or executed under various public private partnership (PPP) agreements. Other forms of models include the popular concession structure, Build-Operate-Transfer (BOT) and also Build Own Operate Transfer (BOOT), Build Transfer Operate (BTO), Design Build Operate Maintain (DBOM), Design Build Finance Operate (DBFO), Operate and Maintain (O\&M), Design and Build (DB), Design Construct Manage and Finance (DCMF), Build Lease and Transfer (BLT), Design Construct, Manage and Finance (DCMF) and several other similar concession acronyms (Boko-haya et al., 2016 \& Eaton and Akbiyikli, 2005).

There exists one rail gauge in Benin and Niger as well as other West African nations. Therefore, Benin should collaborate with regional countries such as Nigeria and Niger to standardize rail gauges for seamless service within and across boundaries through Porto-novo city. Then, rolling stocks further need to be standardized for seamless cross boarder service. Thus, strategic railway investment would be needed.

Regarding the investment in road and bridge sector, the major focus will be to increase the capacity of key national highways including all designated highway sections within the RN1, 2 and 3 as well as priority developments of the bridges located at Calavi-Kpota (rossing Nokoue lake) and Lokpodji (Figure.1 and 2). Major road development activities should therefore focus on improving intermodal connectivity (e.g., physical integration of all feasible modes at strategic 
transportation hubs) and highway safety as well as maintaining roadways for quality service. To improve safety and operational efficiency of all modes including ports (e.g., river, land and sea) and intermodal facilities/terminals, technology should be needed. In this sense, an ITS (Intelligent Transportation Systems) vision for ensuring interoperability of equipments and the systems needs to be developed and a priority base incremental deployment of ITS technologies needs to be guaranteed.

\section{Conclusion and key recommendations}

The presented paper reviews the programs, policies, planning, and development of surface transportation systems (e.g., highway or roadway, waterways and railways) in Porto-novo, Benin Republic. Moreover, it identifies the institutional and planning weaknesses as well as development priority needs from multimodal transportation systems and regional connectivity prospective. Presently, there are inconsistencies between the policies and how various projects are identified, selected and funded making it harder to achieve the different policies goals. Besides it's suggested that a comprehensive and continuous multimodal transportation planning process needs to be developed for the prioritization, the programs selection and infrastructure projects as well as for the analysis and evaluation of transportation policies as whole. In addition, the money borrowed from the multilateral banks and agencies and limited resources need to be used transparently justifying the policy goals and objectives.

As specific recommendations listed below, there is a lot of work to be done in a thorough going manner that lead to the: (1) Need for formal collaboration and coordination among different surface transportation agencies and ministries as well as public participations in the transportation planning and project development process for the unbiased modal developments; (2) Development of maritime and fluvial transport must be given a priority and Nigeria, Togo and Benin should collaborate in the development of cross-border waterway systems for moving freight and passengers and (3) According to the investment priorities and needs, a formula should be developed to allocate annual development program funds for the multimodal developments and modal integration aim.

\section{Acknowledgment}

The authors gratefully acknowledge the financial support received from the University of Southwest Jiaotong (Department of Bridge Engineering) under Project. (No. VP13KJ1101Y14001 and 51378430).

The first author would like to express his sincere gratitude to Prof. Yadong Li for the continuous support of my study and research, for his patience, motivation, enthusiasm, and immense knowledge. Besides, I would like to thank Professors Yongle Li, Changrong Yao and Zhang Xun questions on my work.

My sincere thanks also goes to my labmates for offering me the opportunities in their groups and leading me working on diverse exciting projects. Any opinions, findings, conclusions and recommendations expressed in this publication are those of the authors.

\section{References}

1. D.D. Boko-haya, Y.D. Li, K. Togbenou, S.Z. Liu, C.R. Yao and B. Qiang. Study on strategic planning of road and bridge infrastructure development in city planning: taking Porto-novo city of Benin Republic as example. MATEC Web Conf. (to be published)

2. D.D. Boko-haya, Y.D. Li, S.Z. Liu, C.R. Yao, Q.Q. Xiang \& B. Qiang. Assessment research on capacity strengthening in bridge and road development in the Republic of Benin. (to be published)

3. C.D. Torres and V. Foster. Benin's Infrastructure: A Continental Perspective, pp.5-8, (2011).

4. D.D. Boko-haya, Y.D. Li, C.R. Yao, S.Z. Liu and Q.Q. Xiang. Road and bridge infrastructure development issues in Benin Republic: analysis and perspectives. American Journal of Civil Engineering. 5 (1), pp. 9-15, (2017).

5. D.D. Boko-haya, Y.D. Li, C.R. Yao, Y. Gu, B. Qiang, and Q.Q. Xiang. Development of conceptual model for overcoming the challenges of road and bridge infrastructure development: towards innovative solutions in Benin Republic, Int. J. Eng. Res. Afr. 26, pp. 161-175, (2016). DOI: 10.4028/www.scientific.net/JERA.26.161

6. A. Anais, M. Schut. Discussion on strategy \& urban design for the city of Porto-novo, pp.44-57, (2010).

7. République du Bénin. Etudes nationales de perspectives à long terme, Bénin 2025 alafia, stratégies de développement du Bénin, (2000).

8. El. Samia, B. Cukierman, A. Pringle. Discussion on analysis of urban planning \& development Portonovo, Benin. $2^{\text {nd }}$ edition, pp.22-36, (2010).

9. République du Bénin. Programme d'action du gouvernement (2016-2021), Cotonou, (2016).

10. Republic of Benin. Law $n^{\circ} 98-005$ on the organization of municipalities with special status http://www.decentralisationbenin.org/IMG/pdf_loi_98-005.pdf, 2017.

11. Republic of Benin, Decree $N^{\circ} 2001-092$ of February 20, 2001. Classifying economic, tourist or strategic routes of interest, pp.3-6, (2001).

12. E. Zavadskas, R. Liias, Z. Turskis. Multi-attribute decision making methods for assessment of quality in bridges and road construction: State of the art surveys.Balt.J.RoadBridgeEng.3,pp.152-160, (2008). 